\title{
Retroauricular Thyroidectomy Using a New Flexible, Single-Port Robotic Surgical System
}

\author{
Myung-Chul Lee \\ Department of Otorhinolaryngology-Head and Neck Surgery, Korea Cancer Center Hospital, Korea Institute of Radiological and \\ Medical Sciences, Seoul, Korea
}

\section{새로운 유연성 단일 포트 로봇 수술 시스템을 이용한 후이개 접근 갑상선 절제술 소개 및 문헌고찰}

\author{
이 명 철 \\ 한국원자력의학원 원자력병원 이비인후-두경부외과
}

\author{
Received September 27, 2017 \\ Revised November 8, 2017 \\ Accepted November 8, 2017 \\ Address for correspondence \\ Myung-Chul Lee, MD, PhD \\ Department of Otorhinolaryngology- \\ Head and Neck Surgery, \\ Korea Cancer Center Hospital, \\ 75 Nowon-ro, Nowon-gu, \\ Seoul 01812, Korea \\ Tel $+82-2-970-2358$ \\ Fax $+82-2-970-2450$ \\ E-mail entdok@gmail.com
}

This study aimed to assess a new flexible, single-arm robotic surgical system to retroauricular thyroidectomy. Three fresh cadavers were used. Technical elements of the system and the whole surgical procedures were described in detail. This single-port flexible system could be used to successfully perform retroauricular thyroidectomy. The ideal angle to dock the patient-side cart was at a 90-degree angle to the operating table. When the cannula tip was placed $10-15 \mathrm{~cm}$ away from the skin incision, positioning and full movement of all four instruments without collisions were possible. Flexible three instruments and a stereoscope made the robotic dissection more efficient, safe and time-saving. We report the first preclinical evaluation of an innovative, flexible, single-arm robotic surgical system for retroauricular thyroidectomy. Korean J Otorhinolaryngol-Head Neck Surg 2017;60(12):593-8

Key Words Flexible robotic system · Retroauricular · Robot $\cdot$ Thyroidectomy.

\section{서 론}

최근 갑상선암의 발생률이 눈에 띄게 증가하면서 환자와 의료진의 관심이 많아지고 있고, 이러한 현상에 대한 연구도 많이 늘어나고 있다. ${ }^{1)}$ 이렇게 증가되고 있는 갑상선암의 발생 률은 초음파를 통한 갑상선 검진의 대중화와 연관이 있다. 대부분의 갑상선암은 유두암(papillary thyroid cancer)으로 적절히 치료하면 이환률, 사망률과 재발률이 낮아 예후는 아 주 좋은 편이다. ${ }^{2)}$

Emil Kocher가 1800년대 후반에 개방성 경부 절개 갑상 선 절제술을 고안하고 표준화한 후에 이 술식은 갑상선 절제 술의 주류로 인정받아 왔다. ${ }^{34)}$ 이러한 개방성 갑상선 절제술

This is an Open Access article distributed under the terms of the Creative Commons Attribution Non-Commercial License (http://creativecommons.org/licenses/by-nc/4.0) which permits unrestricted non-commercial use, distribution, and reproduction in any medium, provided the original work is properly cited.
은 경험 있는 외과의에 의해서 행해지면 안전하고 효과적이라 고 평가받아 왔지만, 수술 후 생기는 경부의 상처에 대해 미 용적으로 불만을 가지는 환자들도 많다. ${ }^{5,6}$

이러한 불만을 극복하기 위해 다양한 수술 접근법이 개발 되어 왔다. 최소 침습 비디오 보조 갑상선 절제술(minimally invasive video-assisted thyroidectomy)은 목에 $2 \mathrm{~cm}$ 의 횡 방향 절개를 하고 비디오 내시경을 보면서 수술하기 때문에 박리 범위와 조직 손상, 통증이 적어 회복 기간이 짧다. ${ }^{7.8}$ 이 접근법은 기존 방법에 비해서 절개 길이가 짧지만 켈로이드 체질이나 비후성 반흔의 소인이 있는 환자들에서는 여전히 눈에 띄는 상처가 생길 수 있다는 단점이 있다. 이 술식과는 다르게 경부에 상처를 전혀 안 내기 위해서 원위부에서 접근 (remote access)하는 내시경적 또는 로봇 접근법으로는 경액 와(transaxillary), 경유방(breast), 경액와-유방(axillo-breast), 후이개(retro-auricular), 경구강(transoral) 접근법 등이 있다.-11) 
이 중에서 가장 많이 시행된 것은 Chung 등이 개발한 경액 와 접근법으로 2007년 이후 대한민국에서는 3000예 이상, 전 세계적으로는 6000예 이상 시행되었고, 치료 결과, 미용, 부 작용, 삶의 질 등에서 훌륭한 결과를 보여주고 있다. ${ }^{10,12-16)}$

경액와 접근법을 통한 로봇 갑상선 절제술은 2009년에 미국 에 소개되었지만, 서양인과 동양인의 체구(body mass index) 와 갑상선 병리 조직의 차이, 높은 비용 등의 이유로 많이 시 행되지는 않았다. ${ }^{4,17-20)}$ 하지만 몇몇 기관에서는 목에 상처를 남기고 싶지 않아 하는 환자들을 대상으로 경액와 접근법 로 봇 갑상선 절제술을 여전히 시행하고 있다. ${ }^{2,19,21)}$ 최근에 Terris 등이 후이개 접근법을 소개하였는데 이는 후이개의 절개부 와 갑상선까지 거리가 경액와 접근법에 비교해서 짧기 때문에 박리 범위와 조직 손상이 작고, 배우기가 쉬우며 안전하다는 장점이 있다. ${ }^{22-25)}$

현재까지는 로봇 갑상선 절제술을 시행하기 위하여 1 개의 경직성 양안 입체 내시경(binocular stereoendoscope)과 3개 의 경직성 수술팔(rigid instrument arm)들을 이용하는 다빈 치 로봇 수술 시스템(da Vinci robotic surgical system, Intuitive Surgical Inc., Sunnyvale, CA, USA)을 이용하고 있다. 이 로봇 시스템을 이용한 경액와 접근법에서는 총 4개의 로 봇팔이 액와 절개선을 통하여 수술부로 들어가지만, 후이개 접근법으로는 작업 공간이 협소하기 때문에 일반적으로 1 개 의 내시경과 2 개의 수술팔, 즉 3 개의 로봇팔이 후이개 절개 선을 통해서 들어가게 된다. ${ }^{22,23,26)}$

2014년 4월에 새로운 유연성 단일 포트 로봇 수술 시스템인 다빈치 Sp 수술 시스템(Model SP999, Intuitive Surgical Inc.) 이 처음으로 Food and Drug Administration에 의해서 비뇨 기계 수술에 인증을 받았다. ${ }^{27)}$ 이 시스템은 4 개의 팔이 각각

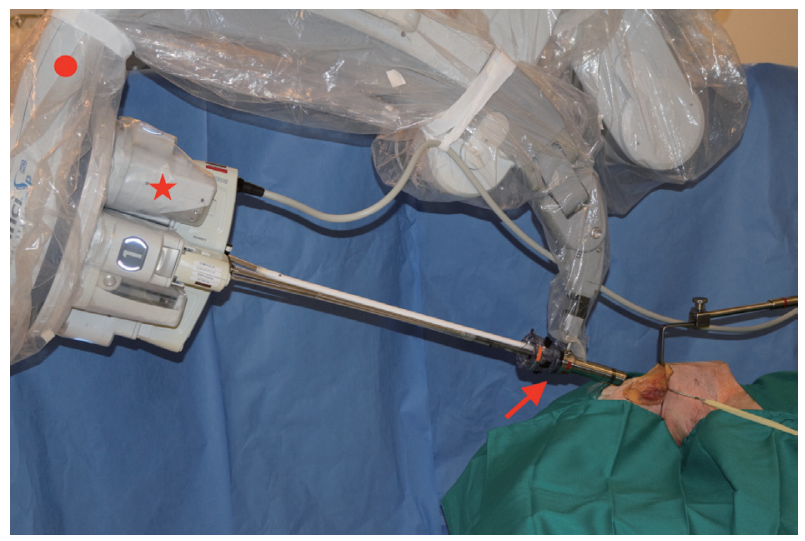

Fig. 1. External view of the flexible single-arm robotic surgical system. Four robotic manipulators (red star) take control of three EndoWrist Sp (Intuitive Surgical, Inc.) instruments and one flexible endoscope within the single instrument arm (red circle). Four instruments are delivered to surgical site through single port (cannula, red arrow).
의 도구를 가지고 수술하는 기존 시스템과 다르게 단일 포트 로 4개의 유연성 팔이 모두 들어가기 때문에 좁은 수술 부위 에서도 수술이 가능하다(Fig. 1). 2015년 10월에는 이 시스템 을 이용하여 편도와 가측 인두벽을 절제하는 최초의 전임상 연구가 행해졌다. ${ }^{28)}$

이번 연구에서 우리는 이 혁신적인 유연성 단일 포트 로봇 시스템을 이용한 후이개 접근 로봇 갑상선 절제술을 최초로 소개하고자 한다.

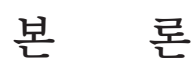

본 연구는 3구의 신선 사체(fresh cadaver)를 이용하여 이 루어졌다. 로봇 시스템이 다르다는 것을 제외하면 Koh 등 ${ }^{24)}$ 과 Terris 등이 소개한 방식대로 준비와 수술 과정을 진행하 였다. $22,23,28)$

사체는 수술 테이블 위에 앙와위로 위치시키고, 머리는 병 변 반대쪽으로 30도 정도 돌린다. 수술 테이블은 역 Trendelenburg 자세로 만들고, 수술자의 위치를 고려하여 반대 방 향으로 돌린다. 절개는 귀에 의해 가려지도록 귀 뒤의 주름 에 인접하게 만들고 후두부의 머리선(hairline) 쪽으로 연결 시킨다. 후두부 머리선 안쪽 $1 \mathrm{~cm}$ 를 따라 아래쪽으로 흉쇄유 돌근(sternocleidomastoid muscle)까지 절개를 연장시킨다. 피부 활경근하 피판(skin-subplatysmal flap)을 쇄골까지 흥쇄 유돌근 앞쪽으로 박리하고, 대이개신경(great auricular nerve) 과 외경 정맥(external jugular vein)을 확인하고 보존한다. 견 갑설골근(omohyoid muscle)을 확인해서 들어올리면 흥설 골근, 흥갑상근과 갑상선을 확인할 수 있게 된다. 외부 고정 견 인 시스템(external fixed retractor system)을 갑상선과 피대 근 사이에 밀어 넣어서 피부근육피판을 들어올리고 작업공 간을 유지하게 된다. 다른 견인기로 흥쇄유돌근을 바깥쪽으 로 견인하고 유연성 로봇 시스템을 준비해서 작업 공간에 위 치시킨다.

\section{다빈치 단일 포트 로봇 수술 시스템(da Vinci single port robotic surgical system)}

기술적인 정보나 스펙은 이전 문헌에 자세히 기술되어 있 다. ${ }^{28,29)}$ 기존 시스템과 비슷하게 차세대 유연성 로봇 시스템 은 수술자 콘솔(surgeon console), 환자측 카트(patient-side cart), 비디오 카트(vision cart)의 세 개 구성요소로 이루어 져 있다. 기존 시스템과의 가장 큰 차이는 자유롭게 움직이 는 유연성 입체 내시경과 3 개의 로봇팔이 4 개의 홀을 가진 단일 포트에 들어가서 작업공간까지 같이 이동한다는 것이 다. 이러한 단일 포트 시스템을 위한 내시경팔과 $6 \mathrm{~mm}$ 수술 
팔(EndoWrist Sp, Intuitive Surgical, Inc.)은 손목과 팔꿈치 관절이 있어 내시경은 뱀의 머리처럼 움직일 수 있고, 수술팔 들은 삼각형 모양을 유지하면서 좁은 공간에서 수술할 수 있 다. 유연성 양안 입체 내시경은 0도에서 30도까지 카메라 각 도를 자유자재로 바꿀 수 있다.

\section{환자측 카트}

4개의 수술 조작기(manipulator)가 유연성 도구와 내시경을 단일 포트 안에서 조절한다(Fig. 1). 포트 클러치(port clutch) 는 수술 보조인이 3 개의 로봇팔과 내시경이 들어 있는 단일 포트를 이동시킬 수 있게 한다. 암 클러치(arm clutch)는 절개 선 주변의 연부조직 손상을 막기 위해 포트를 3차원 공간에 서 이동시키지 않으면서 회전하거나 각도를 틀게 해준다.

\section{수술자 콘솔}

기존 로봇 시스템의 콘솔과 가장 다른 점은 단일 포트를 움 직이기 위한 추가 페달이 있다는 것이다. 또한 새로운 그래픽 유저 인터페이스는 실시간으로 내시경과 3 개의 로봇팔의 3 차원적 위치 관계를 도식적으로 보여 주어서 수술 시 도구 간의 충돌을 방지하는 데 도움을 준다(Fig. 2).

\section{수술 결과}

\section{도 킹}

기존 로봇 수술 시스템을 사용할 때는 환자측 카트의 발판 이 수술 테이블과 30도 정도의 각도를 이뤄야 하고, 견인 시스

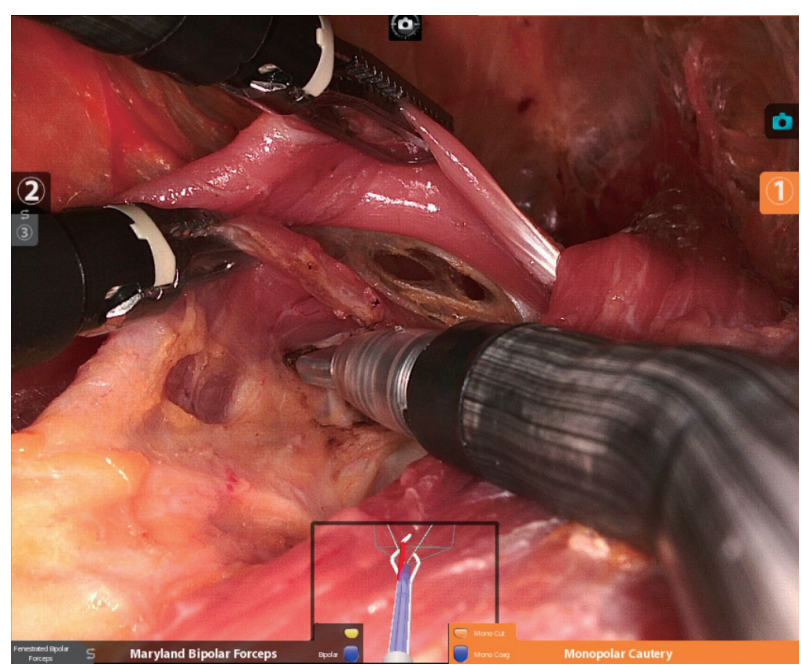

Fig. 2. The surgical console view during retroauricular thyroidectomy using the flexible single-port robotic system. The new graphical user interface in the black box in the lower mid part of stereoscopic display of the surgeon console shows the relationships of the four instruments in a real time.
템과는 평행해야 하지만, 이번 차세대 로봇 시스템에서는 도 구팔(instrument arm)이 270도 회전이 가능하기 때문에 어느 각도에서도 작업공간으로 접근이 가능하다. 수술팔들의 인 체공학적인 면과 수술 보조인의 편의를 고려했을 때 가장 적 절한 환자측 카트의 위치는 수술자의 맞은편에서 수술 테이 블과 90도 각도로 위치하는 것이다.

유연성 입체 내시경, 매릴랜드 겸자(Maryland bipolar forceps), ProGrasp 겸자, 단극성 소작기(monopolar cautery) 등이 도구팔에 부착된 다음 4개의 채널을 가진 $2.5-\mathrm{cm}$ 직경 의 단일 포트 캐뉼라에 장착된다(Fig. 1).

단일 포트 캐뉼라 끝은 후이개 피부 절개선에서 $10 \sim 15 \mathrm{~cm}$ 떨어진 곳에 위치해야 한다. $10 \mathrm{~cm}$ 보다 가깝게 위치하면 기 구들의 첫 번째와 두 번째 관절이 캐뉼라를 벗어나지 못하고, $15 \mathrm{~cm}$ 보다 멀게 위치하면 기구의 길이가 부족해서 반대쪽 갑상선까지 닿지 않는다(Fig. 3). 기존의 로봇 시스템과는 다르 게 본 시스템에서는 단일 캐뉼라가 내시경과 3개의 수술도구 를 후이개 절개선을 통해 갑상선까지 이동시킨다. 캐뉼라와 기구들의 각도는 고정식 견인기와 평행하게 유지하면서 수술 하였으나 사체별로 조금의 각도 조절은 필요하였다.

\section{로봇 갑상선 절제술 술기}

로봇 갑상선 일엽 절제술은 바깥에서 안, 위에서 아래, 그 리고 정중선을 향해 비스듬히 행해진다. 수술은 일단 상부 갑 상선 혈관들을 헤모클립(hemoclip)이나 양극성 소작기로 결 찰하는 것으로 시작한다. 갑상선 상극(upper pole)을 앞쪽으 로 제치고, 하인두수축근을 조심스럽게 아래쪽으로 박리해 나간다. 이 과정에서 상후두신경의 외측 가지를 확인하고 보 존하여야 한다. 갑상선 상극의 뒷부분에서 상부갑상선을 확 인하고 뒤로 박리해서 보존한다. 이 부근에서 반회후두신경이

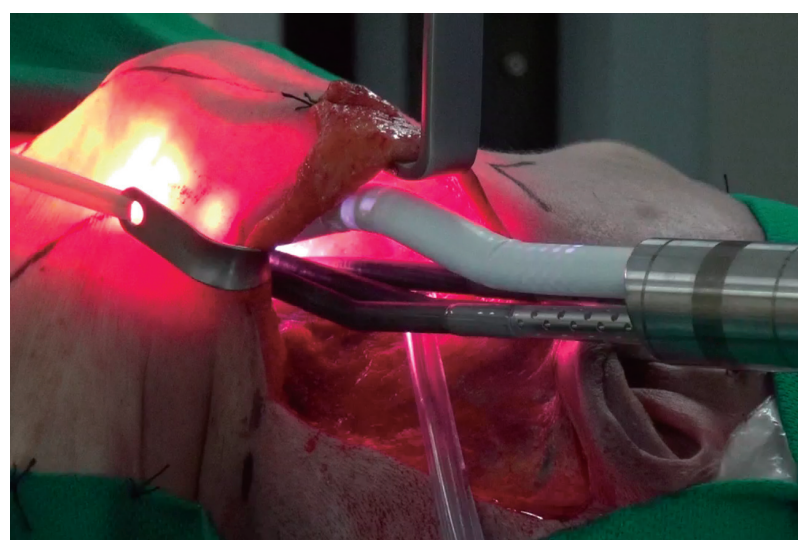

Fig. 3. The external view after docking of the system. The cannula tip was placed $10-15 \mathrm{~cm}$ away from the skin incision line. The flexible three instruments and endoscope moved freely without collisions during dissection at this distance. 
윤상갑상근(cricothyroid muscle)의 아래쪽으로 들어가는 부 분을 확인하고 조심스럽게 보존해서 아래쪽으로 박리해 나간 다(Fig. 4). Berry 인대를 자르고 갑상선을 기관(trachea)에서 분리하고, 갑상선 협부와 아래극(inferior pole)을 박리하면 동측 갑상선 엽절제술이 완성된다. 절제된 일측 갑상선엽은 긴 겸자를 이용하여 후이개 피부 절개선을 통하여 수집한다. 같은 후이개 절개선을 통하여 반대측 갑상선 절제술을 진 행한다. 최대의 수술 시야를 확보하기 위하여 견인 시스템의 블레이드를 조금 더 밀어 넣어야 한다. 동측의 갑상선 절제의

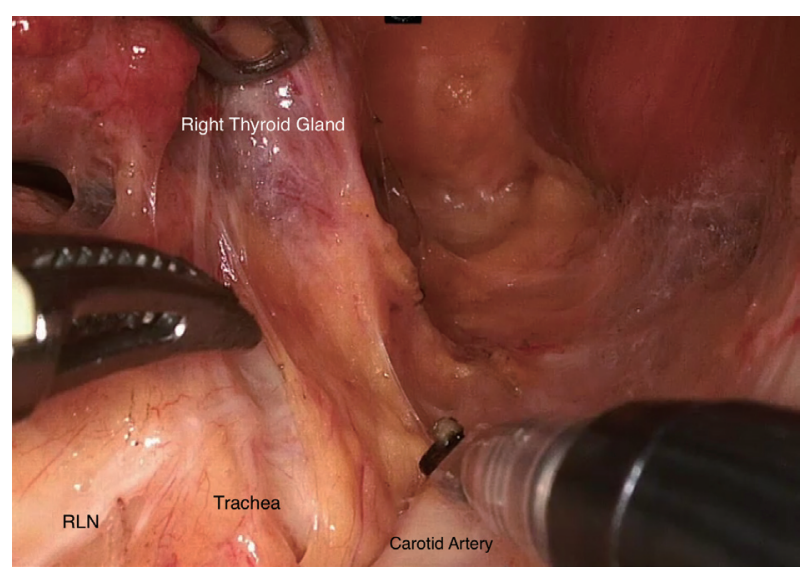

Fig. 4. The surgical view during retroauricular thyroidectomy using the flexible single-port robotic system. Through the right retroauricular incision, right thyroid lobectomy was performed. The right thyroid gland was retracted medially and anteriorly exposing the recurrent laryngeal nerve and Berry's ligament with a ProGrasp forceps. A monopolar cautery and a Maryland bipolar forceps were used to dissect the thyroid gland with care not to damage the recurrent laryngeal nerve. RLN: recurrent laryngeal nerve.

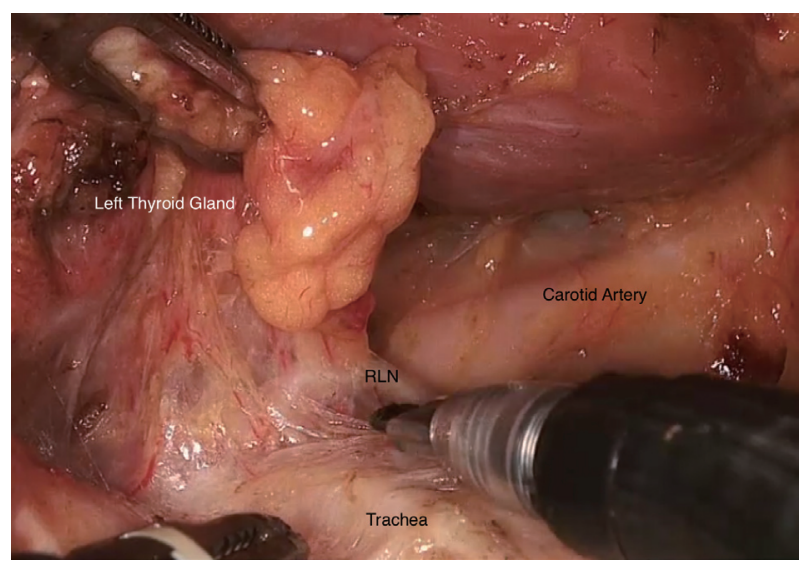

Fig. 5. The surgical view during retroauricular thyroidectomy using the flexible single-port robotic system. Through the right retroauricular incision, left thyroid lobectomy was performed after right lobectomy had been finished. The left thyroid gland was retracted laterally and anteriorly exposing the recurrent laryngeal nerve with a ProGrasp forceps. During dissection of the thyroid gland with a monopolar cautery, a Maryland bipolar forceps were used to retract the cricoid and trachea posteriorly. RLN: recurrent laryngeal nerve.
방향과 다르게 반대측 갑상선 절제술은 기본적으로는 내측 에서 외측으로 수술을 진행하게 된다. 먼저 잘려진 갑상선 협 부를 견인하며 갑상선을 기관에서 박리해 나간다. 윤상연골 을 뒤로 당기면서 상부 갑상선 혈관들을 결찰하고 갑상선 상 극을 윤상갑상근에서 분리한다. 윤상갑상근 아래쪽에서 반 회후두신경을 확인하고, 상부갑상선을 보존한다(Fig. 5). 반 회후두신경을 따라서 아래쪽으로 박리하면서 하부갑상선을 확인하여 보존하고 갑상선 하극을 박리하면 반대측 갑상선 엽절제술이 완성된다.

똑같은 세팅에서 추가적으로 중앙경부림프절 적출술을 시 행할 수도 있다. 양측 총경동맥 사이와 위쪽으로는 설골, 아 래쪽으로는 무명동맥 사이의 림프절들을 제거한다.

기존의 로봇 시스템으로 하는 술식과 다르게 본 시스템으 로는 내시경과 함께 3 개의 로봇팔을 수술 시야 내에서 서로 충 돌이나 동작의 제약 없이 동시에 사용할 수 있다. 뱀의 머리처 럼 움직이는 유연성 입체 내시경은 수술하는 동안 편안한 각 도에서 대상물을 3 차원으로 볼 수 있게 해준다. 후이개 접근 법에서 2 개의 로봇팔만 사용할 수 있는 기존의 로봇 시스템 과는 달리 3개의 로봇팔을 사용함으로써 수술 대상이나 주변 구조물들의 추가적인 견인이나 역견인(counter-traction)이 가능하여 횔씬 효율적인 수술을 가능하게 한다.

\section{고 찰}

다빈치 $\mathrm{Sp}$ 로봇 시스템은 제한된 공간에서 3 개의 팔을 동 시에 사용할 수 있도록 유연성 입체 내시경과 3 개의 $6 \mathrm{~mm}$ 로 봇팔을 단일 포트를 통해 수술 부위까지 전달하는 유연성 단일 포트 수술 로봇 시스템이다. ${ }^{27)}$ 본 연구는 전임상연구로 서 유연성 로봇 시스템을 이용하여 후이개 접근법을 통한 로 봇 갑상선 절제술을 사체에 처음으로 시도하였다.

기존 시스템에서는 도킹할 때에 4 개의 도구팔들을 서로 충 돌하지 않게 위치시키는 게 복잡하고 시간이 드는 작업이었지 만 본 시스템에서는 수술팔들과 내시경을 잡고 제어해주는 도구팔이 하나이고 270도 각도로 회전할 수 있기 때문에 도 킹이 훨씬 단순하고 빠르다. 도킹할 때의 각도는 기존보다 자 유롭게 정할 수 있지만 환자 카트와 수술 침대의 각도가 90도 일 때 수술 보조인과 수술 동안 삽관튜브를 확인해야 하는 마취과 의사에게 가장 큰 공간을 제공할 수 있다. 수술 부위 주변이 잘 정돈되고 넓고 시야가 잘 확보되어야 수술 보조인 이 수술 중간에 필요한 일을 잘 해줄 수 있고, 수술팔들이 의도치 않게 절개선 주변의 피부를 포함한 조직을 손상시키 는 것을 예방할 수 있다.

단일 포트 캐뉼라의 끝이 피부 절개선으로부터 $10 \sim 15 \mathrm{~cm}$ 
정도 떨어져야 수술팔들의 모든 관절이 캐뉼라의 끝을 통과 할 수 있고, 수술 부위에서 서로 충돌 없이 충분한 가동성을 가지고 수술할 수 있다.

본 시스템으로 하는 후이개 접근 갑상선 절제술의 근본적인 개선점은 수술 중에 수술팔 1 개를 더 사용하여 3 개의 로봇 수술팔을 동시에 사용할 수 있다는 것과 유연성 전자 입체 내 시경이 0 30도까지 수술자의 조종으로 움직일 수 있기 때문 에 수술자가 수술 콘솔에서 내시경의 탈착 없이 수술 시야를 마음대로 조절할 수 있다는 것이다. ${ }^{28)}$ 이러한 장점은 수술 시 야를 바꿔야 할 때 많은 시간을 절약할 수 있다.

기존 수술 로봇 시스템으로는 공간의 제약 때문에 수술 중 에 2개의 로봇팔만 사용할 수 있었다. 한쪽의 후이개 절개선 을 통해서 갑상선 전절제술을 할 때에 반대측 갑상선엽은 반 드시 윤상연골이나 기관에 가리기 때문에 이들을 뒤로 젖히 지 않으면 반대측 갑상선엽의 노출이 제한되어서 수술이 불 가능하다. 그래서 수술 보조인은 특히 반대쪽 갑상선을 수술 할 때에 손으로 또는 추가적인 기구를 사용하여 수술을 보 조하여야 했다. ${ }^{24)}$ 새로운 로봇 시스템을 사용하면 세 번째 로 봇팔을 윤상연골과 기관을 뒤로 젖히거나 반대측 갑상선엽 을 앞으로 견인하는 데 쓸 수 있기 때문에 수술 보조인의 도 움 없이도 수술 시 좋은 시야, 안정성(stability), 일관성(consistency), 안전(safety) 등을 제공할 수 있다.

경직성 내시경에서 유연성 내시경으로 바뀜으로써 선명하 고 확대된 3차원 영상을 수술자가 원하는 각도로 제공할 수 있게 되었는데, 이는 고해상도 카메라 모듈을 내시경의 끝에 위치시킬 수 있는 기술의 발전 때문에 가능해졌다. ${ }^{27,28)}$ 반대 측 갑상선엽을 제거할 때나 아래쪽으로 깊이 위치한 기관 주 위 임파선을 절제할 때 이러한 내시경은 대상 부위에 기구 간 의 충돌 없이 더 가까이 접근할 수 있어 수술자가 원하는 적합 한 시야를 제공할 수 있다.

본 시스템과 관련하여 몇 가지 제약들이 있다. 첫째, $6 \mathrm{~mm}$ 직경의 수술팔은 기존 로봇 시스템의 $5 \mathrm{~mm}$ 수술팔보다는 약간 크다. 갑상선과 같은 작은 기관을 수술하기 위한 더 가 늘지만 강성을 유지할 수 있는 로봇팔이 개발된다면 좁은 공 간에서 수술하기가 더욱 수월해질 것이다. 둘째, 기존 로봇 시스템을 이용한 갑상선 절제술에 많이 사용되어 온 하모닉 절단기(harmonic shear)가 본 시스템에는 아직 개발되어 있 지 않다. ${ }^{27)}$ 이 시스템용 하모닉 절단기가 수술에 사용된다면 양극성, 단극성 소작기를 이용한 수술에 비해서 특히 상부, 하부 갑상선 혈관들을 처리할 때 훨씬 효율적이고 안전할 것 이다.

요약하면, 연구진은 새로운 유연성 단일 포트 로봇 시스템 을 이용한 후이개 접근 갑상선 절제술을 인간 사체에서 성공
적으로 시행하였다. 이 시스템은 유연성 입체 내시경과 3 개 의 로봇팔의 동시 사용으로 후이개 접근 갑상선 절제술에서 기존 로봇 시스템을 대체할 수 있을 것이다.

\section{결 론}

본 연구진은 새로운 유연성 단일 포트 로봇 수술 시스템을 이용한 후이개 접근 갑상선 절제술의 전임상 평가를 최초로 보고한다.

\section{REFERENCES}

1) Adam MA, Speicher P, Pura J, Dinan MA, Reed SD, Roman SA, et al. Robotic thyroidectomy for cancer in the US: patterns of use and short-term outcomes. Ann Surg Oncol 2014;21(12):3859-64.

2) Davies L, Welch HG. Current thyroid cancer trends in the United States. JAMA Otolaryngol Head Neck Surg 2014;140(4):317-22.

3) Hegner CF. A history of thyroid surgery. Ann Surg 1932;95(4):48192.

4) Duh QY. Robot-assisted endoscopic thyroidectomy: has the time come to abandon neck incisions? Ann Surg 2011;253(6):1067-8.

5) Sosa JA, Bowman HM, Tielsch JM, Powe NR, Gordon TA, Udelsman $\mathrm{R}$. The importance of surgeon experience for clinical and economic outcomes from thyroidectomy. Ann Surg 1998;228(3):320-30.

6) Giddings AE. The history of thyroidectomy. J R Soc Med 1998;91 Suppl 33:3-6.

7) Miccoli P, Berti P, Materazzi G, Minuto M, Barellini L. Minimally invasive video-assisted thyroidectomy: five years of experience. J Am Coll Surg 2004;199(2):243-8.

8) Terris DJ, Angelos P, Steward DL, Simental AA. Minimally invasive video-assisted thyroidectomy: a multi-institutional North American experience. Arch Otolaryngol Head Neck Surg 2008;134(1):81-4.

9) Lee KE, Rao J, Youn YK. Endoscopic thyroidectomy with the da Vinci robot system using the bilateral axillary breast approach (BABA) technique: our initial experience. Surg Laparosc Endosc Percutan Tech 2009;19(3):e71-5.

10) Kang SW, Lee SC, Lee SH, Lee KY, Jeong JJ, Lee YS, et al. Robotic thyroid surgery using a gasless, transaxillary approach and the da Vinci S system: the operative outcomes of 338 consecutive patients. Surgery 2009;146(6):1048-55.

11) Richmon JD, Holsinger FC, Kandil E, Moore MW, Garcia JA, Tufano RP. Transoral robotic-assisted thyroidectomy with central neck dissection: preclinical cadaver feasibility study and proposed surgical technique. J Robot Surg 2011;5(4):279-82.

12) Holsinger FC, Terris DJ, Kuppersmith RB. Robotic thyroidectomy: operative technique using a transaxillary endoscopic approach without CO2 insufflation. Otolaryngol Clin North Am 2010;43(2): 381-8, ix-x.

13) Ban EJ, Yoo JY, Kim WW, Son HY, Park S, Lee SH, et al. Surgical complications after robotic thyroidectomy for thyroid carcinoma: a single center experience with 3,000 patients. Surg Endosc 2014;28 (9):2555-63.

14) Lee S, Park S, Lee CR, Son H, Kim J, Kang SW, et al. The impact of body habitus on the surgical outcomes of transaxillary singleincision robotic thyroidectomy in papillary thyroid carcinoma patients. Surg Endosc 2013;27(7):2407-14.

15) Lee J, Chung WY. Robotic thyroidectomy and neck dissection: past, present, and future. Cancer J 2013;19(2):151-61.

16) Son H, Park S, Lee CR, Lee S, Kim JW, Kang SW, et al. Factors contributing to surgical outcomes of transaxillary robotic thyroidectomy 
for papillary thyroid carcinoma. Surg Endosc 2014;28(11):3134-42.

17) Kuppersmith RB, Holsinger FC. Robotic thyroid surgery: an initial experience with North American patients. Laryngoscope 2011;121 (3):521-6.

18) Perrier ND. Why I have abandoned robot-assisted transaxillary thyroid surgery. Surgery 2012;152(6):1025-6.

19) Hinson AM, Kandil E, O'Brien S, Spencer HJ, Bodenner DL, Hohmann $\mathrm{SF}$, et al. Trends in robotic thyroid surgery in the United States from 2009 through 2013. Thyroid 2015;25(8):919-26.

20) Gross ND. Commentary: is robotic thyroid surgery worth the learning curve? Otolaryngol Head Neck Surg 2012;147(6):1047-8.

21) Broome JT, Pomeroy S, Solorzano CC. Expense of robotic thyroidectomy: a cost analysis at a single institution. Arch Surg 2012;147(12):1102-6.

22) Terris DJ, Singer MC, Seybt MW. Robotic facelift thyroidectomy: patient selection and technical considerations. Surg Laparosc Endosc Percutan Tech 2011;21(4):237-42.

23) Singer MC, Terris DJ. Robotic facelift thyroidectomy. Otolaryngol Clin North Am 2014;47(3):425-31.
24) Byeon HK, Holsinger FC, Tufano RP, Chung HJ, Kim WS, Koh YW, et al. Robotic total thyroidectomy with modified radical neck dissection via unilateral retroauricular approach. Ann Surg Oncol 2014;21(12): 3872-5.

25) Terris DJ, Singer MC, Seybt MW. Robotic facelift thyroidectomy: II. Clinical feasibility and safety. Laryngoscope 2011;121(8):1636-41.

26) Lee J, Chung WY. Robotic surgery for thyroid disease. Eur Thyroid J 2013;2(2):93-101.

27) The United States Food and Drug Administration. 501(k) Summary: SP999 da Vinci® SpTM Surgical System 2014. http://www.accessdata. fda.gov/cdrh docs/pdf13/K131962.pdf.

28) Holsinger FC. A flexible, single-arm robotic surgical system for transoral resection of the tonsil and lateral pharyngeal wall: nextgeneration robotic head and neck surgery. Laryngoscope 2016;126 (4):864-9.

29) Kaouk JH, Haber GP, Autorino R, Crouzet S, Ouzzane A, Flamand $\mathrm{V}$, et al. A novel robotic system for single-port urologic surgery: first clinical investigation. Eur Urol 2014;66(6):1033-43.

\section{정답 및 해설}

답 (1)

해 설 화농성 갑상선염을 보이는 제4 새성기형의 수술적 적출은 급성 감염을 치료하고 1 2개월 후에 시행한다. 